\title{
Political communication around the world: New trends and threats
}

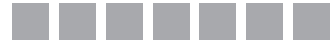 \\ Interview with Prof. Robert M. Entman \\ GEORGE WASHINGTON UNIVERSITY, USA
}

DOI: 10.19195/1899-5101.12.3(24).6

After working with many scholars and travelling across the world, do you see any major differences between Europe and the US in terms of understanding populism, framing or other notions related to political communication that might be caused by either cultural differences or political systems?

The most noteworthy difference is in the popularity of the concept of mediatization. That word is rarely used in US scholarship. The idea that media logic affects political options, communication and behavior is accepted and researched, but not in terms of mediatization. The theoretical development and empirical studies of mediatization come mainly out of Europe. Framing seems to be thoroughly internationalized as a concept. Populism too, but perhaps understood more viscerally in Europe as a potential threat - right-wing populism especially, and particularly if it incorporates neo-Nazism.

Your updated cascading network activation model assumes a heightened impact of economic incentives in the digitalized system - what do you see as the biggest threat for democracy in this regard? Is there anything that either the mainstream media or public can do to avoid spreading fake news and misinformation?

On the first question: the heightened impact of economic incentives is something of a threat to democracy in that it compounds incentives of news organizations to maximize audience size and therefore revenues. These days that means clicks online as well as audience ratings for video broadcasts, cable or satellite. Profit has always been a concern that tends toward reducing journalism quality but it's more intense now as digitalization has increased competition for audience attention, and public broadcasting in many countries suffers quality declines, and newspapers are under severe economic pressure too. A less informed audience by quality journalism is one that's more vulnerable to false and totally fabricated information. 
So on question 2: this is the big issue of the day and an answer would take a book (or more). In brief: one thing that could be done is reinforce the legitimacy and funding of traditional professional journalism and its norms of trying (not always succeeding) to provide balanced perspectives or if coming from a particular ideological view, sincerely attempting to be intellectually honest and based on empirical research. A second tool is pro-democratic civics education in the elementary and secondary schools, which might help inoculate citizens against fake news and propaganda and also build consumer demand for higher quality news. I have an article about how competition isn't necessarily always an enemy of quality journalism ("Improving the Economic Prospects of Newspapers by Enhancing their Contributions to Democracy," International Journal of Press/Politics [2010]).

There is a trend that we observe in Central European Countries, well-developed democracies in Western Europe as well as in the US that right-wing populist content seems to spread with more ease than the left-wing messages. Does your research explain why or do you have suggestions for future projects that might provide the answer?

I think there's some evidence for a correlation of moderate size between attraction to far-right ideology and what used to be called authoritarianism or dogmatism and is now sometimes called fixed worldview (Hetherington and Weiler, Prius or Pickup, 2018). In other words, right-wing people have a moderately stronger tendency toward embracing information that confirms their worldview than do left-wingers or non-ideological folks. That's the most important reason right-wing populist content (fake and otherwise) spreads more easily on right-wing networks. Those on the left who seem to have a more fluid worldview also seem to use on average a wider range of media, at least in the US, than those on the right. The left-leaners are more open to mediated information contradicting their prior views - they're not only plugged into left-leaning media - whereas right-wing people tend more frequently to only connect with other mass and social media networks on the right. Also, right-wing networks are generally more developed, more closely interconnected and better funded, so everything spreads more easily than on less densely connected leftist networks, not to mention the even less densely connected networks of those who are not particularly interested in politics or ideological in orientation.

Why do you think studying information flow in post-truth societies is that important? Do you expect that your model will be constantly evolving in the future or rather that once the internet and social media are included it should serve for many years?

I certainly hope we're not in a post-truth society. Although we've long known (since Karl Mannheim and others) that truth, except in trivial matters, tends to be 
contentious and not clearly the same to everyone, there is still widespread dedication to empirical verification, however imperfect, among honest intellectuals and political elites. To be sure, there are many dishonest ones too. So I would call this not a "post-truth society" but a society where "searching for and trying to verify truth is under more organized assault by powerful organized elites now than in the second half of the twentieth century," at least in many countries that like to think of themselves as Western-style democracies. Of course that's not as catchy.

As to the updated cascade model, it is designed as a starting point for thinking in an organized way that could help scholars develop theoretical and empirical understanding of our rapidly evolving political communication systems. Therefore it will, I certainly hope, evolve. For example, it's possible that the steepness of hierarchy in information flow will decline more than we argue has happened so far, in the recent article updating the cascade model: "Framing in a Fractured Democracy: Impacts of Digital Technology on Ideology, Power and Cascading Network Activation," Journal of Communication, 68(2) (2018) (with N. Usher).

Do you see any emerging trends in political communication studies that you find exceptionally important or on the contrary - are there any spheres that seem to be forgotten or omitted, while they should be researched more (either from the methodological perspective or a specific topic)?

I believe that the large amount of attention now devoted to conceptualizing and measuring and parsing the causes and effects of polarization is important. But we need more research on those who aren't especially interested or ideological. My hope is that more attention will be paid to those who are not polarized, despite this era of polarization. They are sometimes genuinely mixed ideologically (moderates), other times confused or uninterested or poorly informed. In societies like the US where the split between loyal Democrats and Republicans is nearly 50-50 in many districts, it's precisely these citizens who aren't strong ideological and partisan loyalists whose votes decide elections. Where do they get their info? How political are their communications interpersonally and on social media? What news media do they use, if any? How informed and misinformed are they? What leads them to vote or not to vote in different elections? What personality differences do they exhibit from loyalists? Why do some working class citizens identify with an ideology and party (in the US, liberal or progressive ideology and Democratic Party) that claims to care about economic equality and thus to benefit the working class through active government; other working class citizens identify with a party that doesn't claim to care about economic equality but rather about minimal government intervention to maximize economic growth and equal opportunity for all; and still others don't identify or only weakly? The list of relevant questions is long. 
Robert M. Entman is J.B. and M.C. Shapiro Professor Emeritus of Media and Public Affairs and Professor of International Affairs at The George Washington University. He earned his Ph.D. in political science from Yale University. Before GWU he taught at Duke, Northwestern and North Carolina State Universities. His main research interest is the intersection of media, democracy and public policy. He is well-known for research on framing, and for writings on the media's role in race relations, international relations and political scandals. Among many awards, Prof. Entman received a Harvard Goldsmith Book Prize for his book The Black Image in the White Mind (co-authored with Andrew Rojecki) and Humboldt Research Award from the Alexander von Humboldt Foundation of Germany.

Prof. Robert M. Entman was interviewed online by Julia Trzcińska, University of Wrocław, in November 2018. 